\title{
Use of biological based therapy in patients with cardiovascular diseases in a university-hospital in New York City Larisa Chagan*1, Diane Bernstein ${ }^{\dagger 2}$, Judy WM Cheng ${ }^{\dagger 1}$, Harold L Kirschenbaum ${ }^{\dagger 1}$, Vitalina Rozenfeld ${ }^{\dagger 3}$, Gina C Caliendo ${ }^{\dagger 4}$, Joanne Meyer ${ }^{\dagger 4}$ and Bernard Mehl ${ }^{\dagger 4}$
}

\begin{abstract}
Address: ${ }^{1}$ Division of Pharmacy Practice, Arnold \& Marie Schwartz College of Pharmacy and Health Sciences, Long Island University, Brooklyn New York, USA, ${ }^{2}$ At the time of the study, Arnold \& Marie Schwartz College of Pharmacy and Health Sciences, Long Island University, Brooklyn New York, USA, ${ }^{3}$ Medical Science Liaison, Watson Laboratories, Inc., Morristown, New Jersey, USA and ${ }^{4}$ Department of Pharmacy, Mount Sinai Hospital, New York, New York, USA

Email: Larisa Chagan* - lchagan@aol.com; Diane Bernstein - dbernstein@yahoo.com; Judy WM Cheng - judy.cheng@liu.edu; Harold L Kirschenbaum - harold.kirschenbaum@liu.edu; Vitalina Rozenfeld - vita@e-iz.com; Gina C Caliendo - gina.caliendo@mssm.edu; Joanne Meyer - joanne.meyers@mssm.edu; Bernard Mehl - bernardmehl@aol.com

* Corresponding author †Equal contributors
\end{abstract}

Published: 03 March 2005

BMC Complementary and Alternative Medicine 2005, 5:4 doi:10.1 I86/1472-6882-5-4
Received: 04 May 2004

Accepted: 03 March 2005

This article is available from: http://www.biomedcentral.com/1472-6882/5/4

(C) 2005 Chagan et al; licensee BioMed Central Ltd.

This is an Open Access article distributed under the terms of the Creative Commons Attribution License (http://creativecommons.org/licenses/by/2.0), which permits unrestricted use, distribution, and reproduction in any medium, provided the original work is properly cited.

\begin{abstract}
Background: The use of complementary and alternative products including Biological Based Therapy (BBT) has increased among patients with various medical illnesses and conditions. The studies assessing the prevalence of BBT use among patients with cardiovascular diseases are limited. Therefore, an evaluation of BBT in this patient population would be beneficial. This was a survey designed to determine the effects of demographics on the use of Biological Based Therapy (BBT) in patients with cardiovascular diseases. The objective of this study was to determine the effect of the education level on the use of BBT in cardiovascular patients. This survey also assessed the perceptions of users regarding the safety/efficacy of BBT, types of BBT used and potential BBTdrug interactions.
\end{abstract}

Method: The survey instrument was designed to assess the findings. Patients were interviewed from February 200I to December 2002. 198 inpatients with cardiovascular diseases (94 BBT users and 104 non-users) in a university hospital were included in the study.

Results: Users had a significantly higher level of education than non-users (college graduate: 28 [30\%] versus 12 [I2\%], $\mathrm{p}=0.003)$. Top $10 \mathrm{BBT}$ products used were vitamin $\mathrm{E}$ [4I $(43.6 \%)$, vitamin C [30(31.9\%)], multivitamins [24(25.5\%)], calcium [19(20.2\%)], vitamin B complex [17(18.1\%)], fish oil [I2(I2.8\%)], coenzyme Q10 [II(II.7\%)], glucosamine [10(10.6\%)], magnesium [8(8.5\%)] and vitamin D [6(6.4\%)]. Sixty percent of users' physicians knew of the BBT use. Compared to nonusers, users believed BBT to be safer $(p<0.00 \mathrm{I})$ and more effective $(\mathrm{p}<0.00 \mathrm{I})$ than prescription drugs. Forty-two potential drug-BBT interactions were identified.

Conclusion: Incidence of use of BBT in cardiovascular patients is high (47.5\%), as is the risk of potential drug interaction. Health care providers need to monitor BBT use in patients with cardiovascular diseases. 


\section{Background}

The use of complementary and alternative medicine (CAM), defined by the United States National Center for CAM as a group of diverse medical and health care systems, practices, and products that are not presently considered to be a part of conventional medicine, has grown tremendously in the United States [1-4]. A recent national survey reported that four out of every ten Americans used at least one form of CAM, and one out of five used prescription medications together with CAM [3]. The prevalence is even higher in patients with chronic medical problems (for example, 28 to $90 \%$ in patients with arthritis, $11-56 \%$ in those with cancer, $60 \%$ in patients with asthma and $67.8 \%$ in patients with human immunodeficiency virus) [5-11]. Biological based therapies (BBT) is an important type of CAM and is defined by the National Center for CAM as use of substances found in nature, such as herbs, foods, and vitamins. BBT is the second most commonly utilized CAM, with the first being prayer therapy [2].

Similar to other chronic medical conditions, patients suffering from a variety of cardiovascular diseases including coronary heart disease, congestive heart failure, stroke, arrhythmia and congenital cardiovascular defects, may also be looking to CAM to prevent or treat their illnesses. This is particularly likely since a number of BBT products including vitamin $\mathrm{E}$, vitamin $\mathrm{C}$, beta-carotene, fish oils, and coenzyme Q10 have been evaluated for prevention and/or treatment of cardiovascular diseases [12-25].

Despite a wide array of available BBT for cardiovascular conditions, studies evaluating the prevalence of usage of these agents are limited [21-25]. As CAM, in general, has become widely accessible to the public, and BBT may be purchased in pharmacies, health food stores and supermarkets, it is difficult to control patient usage of these products. In addition, the likelihood for adverse effects and interactions between conventional therapies and BBT places patients using such products at an increased risk of adverse drug events. It is, therefore, important to examine patient usage so as to advise and monitor them properly. Among the studies conducted to-date that included patients with a broad spectrum of cardiovascular diseases, few focused only on BBT. The studies examined different factors that may determine BBT use, but none of them examined the potential for side effects and drug interactions with other prescription and non-prescription medications that the patients were utilizing. Since patients with cardiovascular conditions consume many prescription medications with narrow therapeutic indexes and extensive drug interaction profiles $[26,27]$, it is important to look at the prevalence of use and potential drug interactions in a cohort of cardiovascular patients.
The primary objective of this study was to determine the effect of the education level on the use of BBT in cardiovascular patients. The study also investigated the attitudes and beliefs towards BBT by patients with cardiovascular diseases. In addition, patient perceptions regarding the safety and efficacy of BBT, common BBT used and a list of potential BBT-drug interactions were reviewed.

\section{Methods}

This is a cross-sectional, descriptive study utilizing structured interviews to assess the level of education, usage, beliefs and attitudes towards BBT among inpatients with cardiovascular diseases. The study was conducted in the Cardiac Care Center at the Mount Sinai Hospital, New York, USA from February 2001 to December 2002. Participants provided informed consent and were interviewed by one of the investigators. To maintain consistency of the interview and to prevent interviewer bias, a scripted letter was drafted for the investigators to invite the patients to participate in the study and to explain the process of the study. After a patient was enrolled, an investigator read the survey questions verbatim to the patient and tried not to elaborate whenever possible. Patients were included in the study if they had at least one of the following diagnoses: cardiovascular disease(s) including congestive heart failure, coronary heart disease, thromboembolic diseases, valvular heart disease, arrhythmia, vascular aneurysm, peripheral vascular disease, pulmonary hypertension, congenital heart disease and post heart transplant. Additional inclusion criteria included being 18 years of age or older, English speaking, no documented cognitive deficits precluding the patient from understanding the interviewer, and willingness to provide an informed consent. Prior to patient contact, the attending physicians of the eligible patients were contacted and informed about the study. If the attending physicians chose not to have their patients participate in the study, the patients were not included. Upon agreement of the physicians, subjects were invited to participate and were asked to sign an informed consent at their convenience prior to being interviewed. This study was approved by the Institutional Review Boards of Mount Sinai Hospital and Long Island University.

\section{Biological based therapy survey}

Utilizing a structured instrument (see Additional file 1), eligible subjects were interviewed by one of the investigators during their stay at the hospital. The BBT survey was modified and adapted from a previously published survey [6]. The participants could choose to answer or not to answer any question at their discretion, and could discontinue their participation in the study at any time during the interview. During the interview, demographic data, including age, gender, race, marital status, level of education, annual income, and working status, were collected. 
Additionally, history of cardiovascular and other medical conditions, and medications utilized were recorded. The definition of BBT in this study was similar to that defined by the United States National Center for CAM, which included all herbal supplements, vitamins and mineral supplements. The patients' attitudes and beliefs towards BBT were assessed by asking them about their perceived safety and efficacy of BBT. The side effects and potential drug/food interactions listed by the patients were compared against those listed in the MicroMedex ${ }^{\circledast}$ Database [28]. The patients' assessments of benefits of BBT as compared with conventional medicine were recorded. Additionally, the participants were asked whether they reported the use of BBT to their physicians, pharmacists, or other healthcare professionals. A review of patients' medical records was performed to collect data about patients' cardiovascular diseases and to confirm medications used. Although, the identity of the participants in this research study was kept confidential, patients were notified in the informed consent process that if potential BBT-prescription medication interactions were identified, their physicians would be notified.

\section{Statistical analysis}

For this study to have an 80 percent power to detect a 20 percent clinically significant difference in determining factors of BBT use such as education level between the users and non-users of BBT, and establishing a p value of $<0.05$ as the level of statistical significance, approximately 200 patients (100 patients in each group) needed to be enrolled. For demographic parameters, continuous variables were compared between the two groups using Students' t-test and categorical variables were compared using chi-square. Attitudes and beliefs regarding the safety and efficacy of BBT were compared between the two groups using a chi-square test for categorical data and Students' t test for Likert-type scale questions. The BBT products used by cardiovascular patients were recorded and the likelihood of potential drug interactions between BBT and other medications the patients were taking were described. Statistical analyses were conducted using Statistical Product and Service Solutions program (SPSS ${ }^{\circledast}$ for Windows, Rel. 10.01 1999).

\section{Results}

A total of 200 patients who were admitted to the Cardiac Care Center at Mount Sinai Hospital were enrolled into the study. All the physicians approached agreed to have their patients participate in the survey. Two of the patients were, eventually, excluded from data analysis due to incomplete survey data. Of the remaining 198 patients, 94 $(47.5 \%)$ reported BBT use at some point in their lifetime and $84(42 \%)$ reported using such products during the immediate 12 months prior to the survey. Of the 94 patients who used BBT, 32\% reported using the products all the time.

Table I: Demographic Characteristics of Study Subjects

\begin{tabular}{|c|c|c|c|}
\hline & Users (\%) & Nonusers (\%) & $\mathrm{p}$ value \\
\hline$N=198$ & $94(47.5)$ & $104(52.5)$ & \\
\hline $\mathbf{A g e}^{2}$ & $61.4 \pm 16.7$ & $58.7 \pm 16.3$ & NSS \\
\hline Gender & & & NSS \\
\hline Male & $5 I(54)$ & $67(64)$ & \\
\hline Female & $43(46)$ & $37(36)$ & \\
\hline Race & & & NSS \\
\hline White & $53(56)$ & $46(44)$ & \\
\hline Black & $19(20)$ & $27(26)$ & \\
\hline Hispanic & $12(13)$ & $18(17)$ & \\
\hline Other ${ }^{3}$ & $10(11)$ & $13(7)$ & \\
\hline Education & & & 0.0006 \\
\hline$<$ High school & $12(13)$ & $28(27)$ & \\
\hline High school & $23(24)$ & $42(40)$ & \\
\hline Some college & $18(19)$ & $12(12)$ & \\
\hline College Graduate & $28(30)$ & $12(12)$ & \\
\hline Graduate School & $13(14)$ & $8(8)$ & \\
\hline Annual Household Income & & & NSS \\
\hline$<\$ 10,000$ & $17(27)$ & $19(30)$ & \\
\hline$\$ 10,000-\$ 30,000$ & $12(19)$ & $15(23)$ & \\
\hline$\$ 30,000-\$ 50,000$ & $8(13)$ & $14(22)$ & \\
\hline$\$ 50,000-\$ 75,000$ & $15(23)$ & $7(11)$ & \\
\hline$\$ 75,000-\$ 100,000$ & $4(6)$ & $4(6)$ & \\
\hline$>\$ 100,000$ & $5(13)$ & $5(8)$ & \\
\hline
\end{tabular}

Ilifetime use of BBT;2 mean age \pm standard deviation (range);

${ }^{3}$ Asian/Pacific Islander/Indian 
Table 2: Distribution of Cardiovascular and Noncardiovascular Diseases

\begin{tabular}{|c|c|c|c|}
\hline & Users & Nonusers & p value \\
\hline Average number of diseases & 4 & 3 & NSS \\
\hline Range & $1-10$ & $1-8$ & \\
\hline Average number of cardiovascular diseases & 3 & 3 & NSS \\
\hline Arrhythmia & 25 & 32 & \\
\hline Congestive Heart Failure & 38 & 52 & \\
\hline Coronary Heart Disease & 45 & 54 & \\
\hline Hyperlipidemia & 31 & 43 & \\
\hline Hypertension & 56 & 65 & \\
\hline Other ${ }^{1}$ & 12 & 14 & \\
\hline Post-heart Transplant Recipient & I & 2 & \\
\hline Thromboembolic Disease & 13 & 16 & \\
\hline Valvular Heart Disease & 11 & 14 & \\
\hline Average number of noncardiovascular diseases & 2 & I & NSS \\
\hline Arthritis & 25 & 17 & \\
\hline Cancer & 3 & 4 & \\
\hline Diabetes Mellitis & 33 & 33 & \\
\hline Gastrointestinal Disease & 19 & 13 & \\
\hline Hypothyroidism & 5 & 11 & \\
\hline Nervous System Disorder & 8 & 9 & \\
\hline Ocular Disease & 6 & 6 & \\
\hline Other ${ }^{2}$ & 30 & 13 & \\
\hline Pulmonary Disease & 12 & 13 & \\
\hline Renal Disease & 7 & 12 & \\
\hline
\end{tabular}

laneurysm, peripheral vascular disease, infective endocarditis, pulmonary hypertension, congenital heart disease;

2allergic rhinitis, scleroderma, systemic lupus erythematosis, Raynaud's disease, benign prostatic disease, osteoporosis

\section{Demographic characteristics}

The demographic and socioeconomic characteristics of the total sample are presented in Table 1 . The mean age of surveyed participants was $60.0 \pm 16.5$ years, and their ages were normally distributed ranging from 19 to 102 years of age. The overall sample consisted of 118 (59.6\%) men and $80(40.4 \%)$ women.

Overall, education level significantly influenced the use of $\mathrm{BBT}, \mathrm{p}=0.0006$. Among users, more patients had college degrees $(28[30 \%])$ as compared with nonusers, (12 [12\%], $\mathrm{p}=0.003)$. In contrast, $42(40 \%)$ nonusers finished high school versus $23(24 \%)$ of users, $\mathrm{p}=0.023$. There were no significant differences between users and nonusers in other demographic variables.

\section{Cardiovascular diseases, other medical conditions and medications used}

The distribution of cardiovascular and noncardiovascular diseases reported by the sample is presented in Table 2 . The mean number of disease diagnoses carried by users and nonusers were 4 (range $1-10$ ) and 3 (range $1-8$ ), respectively, $\mathrm{p}=0.723$, while the mean number of cardiovascular diagnoses for users versus nonusers were 3 (range $1-6$ ) and 3 (range $1-5$ ), respectively, $p=0.134$. The most common cardiovascular conditions diagnosed in users and nonusers were hypertension, 56 (24\%) and 65 $(27 \%)$, followed closely by coronary heart disease, 45 $(19 \%)$ and 54 (18\%), respectively. Distribution of other cardiovascular diseases between users and nonusers was similar as well. Similarly, the mean number of noncardiovascular diagnoses reported by users and nonusers of BBT were not significantly different: 2 (range $1-5$ ) and 1 (range $1-5$ ), respectively, $\mathrm{p}=0.288$.

The mean number of traditional prescription and nonprescription medications taken by the users of BBT ( 7 [range $1-15])$ and nonusers (7 [range 0-18]) was not significantly different, $\mathrm{p}=0.445$. The most common cardiovascular medications prescribed for both users and nonusers were diuretics $(71 \%, 73 \%)$, followed by aspirin $(56 \%$, $43 \%)$ and beta-blockers (49\%, 50\%). The cardiovascular and noncardiovascular medications taken by both groups were not different.

\section{Types and patterns of BBT use}

The BBT products utilized by cardiovascular patients are presented in Table 3 . The mean number of BBT products utilized by cardiovascular patients was two. Vitamin E (41, [44\%]) was the most commonly utilized BBT, followed by vitamin $\mathrm{C}$, $(30[32 \%])$. The prevalence of the remaining BBT is summarized in Table 3. 
Table 3: All Biological Based Therapies Utilized by Cardiovascular Patients (at any time)

\begin{tabular}{|c|c|c|}
\hline Product & Number & Reasons for Use (per patient) \\
\hline AA\#5 (anti-arthritis) & I & treat arthritis \\
\hline Acidophillus & I & health \\
\hline Aloe vera & 4 & headache, stomach gas, skin pigmentation \\
\hline Atomic Drops & 1 & treat headache \\
\hline Bee Pollen & I & prevent cold \\
\hline Beta carotene & 5 & maintain good health, energy, improve heart contraction \\
\hline Bioflavinoid & I & bone health instructed by chiropractor \\
\hline Calcium & 19 & supplement, prevent osteoporosis, improve heart function \\
\hline Chamomile & 2 & stomach ache, improve heart condition \\
\hline Chromium picolante & 2 & supplement for heart condition, muscle strength \\
\hline Coenzyme Q 10 & II & improve heart contraction, supplement to diet \\
\hline Dexatrim & 1 & weight lost \\
\hline DHEA $^{\prime}$ & I & supplement \\
\hline Echinacea & 5 & prevent or treat cold, flu, stay healthy, boost immune system \\
\hline Fish Oil & 12 & decrease cholesterol, maintain circulation and good health, scleroderma \\
\hline Folic Acid & 3 & supplement, help with heart condition, sickle cell anemia \\
\hline Garlic & 5 & decrease cholesterol, help maintain good health \\
\hline Ginkgo biloba & 5 & antioxidant, enhance memory, energy \\
\hline Ginseng & 4 & increase energy, stamina, virility \\
\hline Glucosamine/chondroitin & 10 & treat arthritis, decrease joint pain \\
\hline Golden seal & I & body cleaner \\
\hline Grapeseed oil & I & preserve health \\
\hline Green tea & 3 & decrease cholesterol, improve circulation \\
\hline Mixed herbal tea & I & Sooth stomach upset, anxiety \\
\hline Insulin leaf tea & I & diabetes \\
\hline Iron supplement & 4 & anemia, increase energy \\
\hline Lecithin & 2 & improve heart condition and circulation, decrease cholesterol \\
\hline Alpha-Linolenic acid & I & improve heart condition \\
\hline Magnesium & 8 & supplement, antioxidant, improve metabolism, improve heart function \\
\hline Multivitamins & 24 & supplement, energy, sickle cell anemia \\
\hline Primrose oil & I & scleroderma \\
\hline Saint John's Wart & I & depression \\
\hline Saw palmetto & I & for prostate health \\
\hline Selenium & 4 & antioxidant, supplement, improve heart condition \\
\hline Strong bark & 1 & help with heart condition \\
\hline Valerian & 4 & decrease anxiety, improve sleep, to decrease blood pressure \\
\hline Vitamin B complex & 17 & supplement, improve heart condition, decrease leg cramps, energy \\
\hline Vitamin $\mathrm{B} 12$ & 2 & supplement, anemia \\
\hline Vitamin C & 30 & $\begin{array}{l}\text { antioxidant, supplement, help with heart condition, improve circulation, strengthen immune system, } \\
\text { prevent or treat cold }\end{array}$ \\
\hline Vitamin E & 41 & $\begin{array}{l}\text { antioxidant, supplement, help with heart condition, increase energy, decrease cholesterol, improve } \\
\text { circulation, thin blood, treat hypertension }\end{array}$ \\
\hline Yohimbine & 1 & increase energy, stamina, virility \\
\hline Zinc & 4 & supplement \\
\hline
\end{tabular}

Idehydroepiandrosterone

The patients reported that their physicians were aware of their BBT use in $60 \%$ of the instances and pharmacists were aware in $32 \%$ of the cases. Only $33 \%$ of users reported that they were asked about BBT use during a history/physical examination by a health care professional. The patients were not surveyed about their pharmacists' assessments of BBT use.

\section{Perceived benefits and attitudes towards BBT}

A greater percentage of users (74.5\%) of BBT reported that they believed these products to be safe substances as compared with nonusers $(26.2 \%), \mathrm{p}<0.001$. Likewise, significantly more users believed that BBT was effective (70.2\%) compared to nonusers (30.1\%), $\mathrm{p}<0.001$. More nonusers $(72 \%)$ than users $(45 \%)$ did not know whether BBT products work better, as well as, or worse than traditional medications, $\mathrm{p}<0.001$. More users than nonusers believed 
Table 4: Potential Drug-Biological Based Therapies Interactions \& Management

\begin{tabular}{|c|c|c|c|c|c|}
\hline Medication & $\begin{array}{l}\text { Alternative } \\
\text { Pharmacotherapy } \\
\text { Product }\end{array}$ & Potential Interaction and Management & $\begin{array}{l}\text { Number of } \\
\text { Patients }\end{array}$ & Onset ${ }^{28 *}$ & $\begin{array}{l}\text { Level of } \\
\text { Severity }^{28}\end{array}$ \\
\hline Warfarin & Green tea & $\begin{array}{l}\text { Green tea may antagonize warfarin effects. Monitor } \\
\text { INR. }\end{array}$ & I & Delayed & Moderate \\
\hline Warfarin & Coenzyme Q 10 & $\begin{array}{l}\text { Coenzyme Q } 10 \text { may have procoagulant effects and may } \\
\text { decrease response to warfarin. } \\
\text { Monitor INR. }\end{array}$ & 2 & Delayed & Moderate \\
\hline Warfarin & Vitamin E & $\begin{array}{l}\text { Vitamin E may potentiate warfarin effects. Monitor INR } \\
\text { and signs and symptoms of bleeding. }\end{array}$ & 5 & Delayed & Moderate \\
\hline Warfarin & Garlic & $\begin{array}{l}\text { Garlic has antiplatelet effects, and risk of bleeding may } \\
\text { be increased. } \\
\text { Monitor INR and signs and symptoms of bleeding. }\end{array}$ & 1 & Delayed & Major \\
\hline Warfarin & Ginkgo biloba & $\begin{array}{l}\text { Ginkgo inhibits platelet aggregation, risk of bleeding may } \\
\text { be increased. } \\
\text { Monitor INR and signs and symptoms of bleeding }\end{array}$ & 2 & Delayed & Major \\
\hline Warfarin & Fish oils & $\begin{array}{l}\text { Concomitant use of warfarin and fish oils may increase } \\
\text { risk of bleeding. } \\
\text { Monitor INR and signs and symptoms of bleeding. }\end{array}$ & 1 & Not specified & Not specified \\
\hline Aspirin & Vitamin E & $\begin{array}{l}\text { Coadministration of vitamin } \mathrm{E} \text { and aspirin may increase } \\
\text { the risk of bleeding. Monitor for signs and symptoms of } \\
\text { bleeding }\end{array}$ & 16 & Not Specified & Not specified \\
\hline Aspirin & Garlic & $\begin{array}{l}\text { Additive antiplatelet effects may occur with } \\
\text { coadministration of garlic and aspirin, risk of bleeding } \\
\text { may be increased. Monitor for signs and symptoms of } \\
\text { bleeding }\end{array}$ & 1 & Delayed & Moderate \\
\hline Aspirin & Fish oils & $\begin{array}{l}\text { Concomitant use of aspirin and fish oils may increase } \\
\text { risk of bleeding. } \\
\text { Monitor for signs and symptoms of bleeding }\end{array}$ & 3 & Not specified & Not specified \\
\hline Aspirin & Ginko biloba & $\begin{array}{l}\text { Ginkgo inhibits platelet aggregation; risk of bleeding may } \\
\text { be increased. } \\
\text { Monitor for signs and symptoms of bleeding. }\end{array}$ & 1 & Delayed & Major \\
\hline Clopidogrel & Vitamin E & $\begin{array}{l}\text { Concomitant use of vitamin E and clopidogrel may } \\
\text { increase the risk of bleeding. Monitor for signs and } \\
\text { symptoms of bleeding }\end{array}$ & 5 & Not specified & Not specified \\
\hline Clopidogrel & Garlic & $\begin{array}{l}\text { Additive antiplatelet effects may occur, risk of bleeding } \\
\text { may be increased. Monitor for signs and symptoms of } \\
\text { bleeding }\end{array}$ & 1 & Delayed & Major \\
\hline Clopidogrel & Coenzyme Q & $\begin{array}{l}\text { Coenzyme Q } 10 \text { may have procoagulant effects, may } \\
\text { partially antagonize antiplatelet effect of clopidogrel. }\end{array}$ & I & Not specified & Not specified \\
\hline Insulin & Insulin leaf & $\begin{array}{l}\text { Enhanced hypoglycemic effects. } \\
\text { Patient was advised to discontinue insulin leaf while } \\
\text { receiving insulin for glycemic control. }\end{array}$ & I & Delayed & Moderate \\
\hline Paroxetine & Saint John's Wort & $\begin{array}{l}\text { Saint John's Wort induces cytochrome P450 3A4 } \\
\text { enzyme and has mechanism of action similar to } \\
\text { serotonin reuptake inhibitors. } \\
\text { Administering it concomitantly with paroxetine will } \\
\text { enhance the toxicity of paroxetine. Patient was advised } \\
\text { to discontinue the use of Saint John's Wort }\end{array}$ & I & Rapid & Severe \\
\hline
\end{tabular}

INR = International Normalized Ratio

* Delayed onset of interactions occurs after multiple doses of both agents.

that BBT works as well as traditional medications $(30.9 \%$ versus $9.7 \%, \mathrm{p}<0.001)$. Concerning adverse effects, more users $(44.7 \%)$ of BBT than nonusers $(17.5 \%)$ believed that BBT causes fewer side effects than traditional medications, $\mathrm{p}<0.001$. At the same time, $32.2 \%$ of users and $62.1 \%$ of nonusers did not know whether BBT causes more or fewer side effects than traditional prescription medications, $\mathrm{p}<0.001$.

\section{Potential drug-BBT interactions}

Examination of patients' prescription and nonprescription medication profiles and BBT utilized, revealed 42 potential drug-BBT interactions. The onset of the interaction and the degree of severity were classified according to that used by the MicroMedex HealthCare Series Integraded Index [28] and the published literature [29-43]. Suspected or potential interactions were communicated 
to the patients and their primary physicians. The most common interaction identified was coadministration of aspirin and vitamin E (16 cases) that could potentially result in an increased risk of bleeding due to additive inhibition of platelet aggregation [29-31]. Similar effects may result from coadministration of clopidogrel and vitamin $\mathrm{E}$; this potential interaction was recognized in five cases [31]. Five instances of potential interaction between warfarin and vitamin $\mathrm{E}$ were identified and close monitoring of the International Normalized Ratio (INR) was recommended [32-34]. A list of other potential drug-BBT interactions that were identified is presented in Table 4 .

\section{Discussion}

Despite a wide array of available BBT for cardiovascular conditions, studies evaluating the prevalence of their usage are limited. A review of the literature at the time of study initiation (January 2001) and more recently (June 2004) identified five studies in this area, and only a few included a broad spectrum of cardiovascular disease patients [21-25].

Wood et al. conducted a telephone survey in 107 patients randomly selected from the "Improving Cardiovascular Outcomes in Nova Scotia" database [24]. A majority of patients (64\%) in this study utilized CAM. Ackman and colleagues evaluated the patterns of BBT use by patients with congestive heart failure (CHF) [21]. Out of $180 \mathrm{CHF}$ patients, 59\% used vitamins and minerals and 38\% used herbal or health food products. Liu and associates evaluated the prevalence of CAM used in 263 patients undergoing cardiovascular surgery [22]. Seventy-five percent of respondents utilized CAM including vitamins (53.6\%), nutritional therapy (17.1\%) and herbs (9.9\%). Compared with non-CAM users, users were older $(\mathrm{p}=0.027)$, belonged to the Caucasian racial group, $(\mathrm{p}=0.001)$ and had a higher level of education ( $\mathrm{p}=0.017)$. Additionally, the evaluation of attitudes towards the effectiveness of CAM revealed that users were more likely to believe that CAM would work in a complimentary manner with conventional medical treatments, $\mathrm{p}<0.05$. Furthermore, more users than nonusers believed that CAM would promote general health and wellness, $\mathrm{p}<0.05$. Of the patients surveyed, only $17 \%$ reported discussing CAM with their medical doctors. Another recent study evaluated the use of CAM among 246 patients attending a cardiac clinic prior to cardiac surgery [23]. A total of 182 $(80.9 \%)$ patients used CAM, and $12.9 \%$ utilized megavitamins. Another study, conducted in Canada, focused on the use of over-the-counter medications and herbal products among patients with cardiac diseases, the majority of whom were diagnosed with coronary artery disease $(74 \%)$ [25]. The authors reported that $23 \%$ of the patients used multivitamin or multivitamin/mineral products. Overall, the results of these five studies confirm a high prevalence of all kinds of CAM used, including BBT among patients with cardiovascular diseases.

\section{Biological based therapy used by cardiovascular patients}

In our study, the lifetime prevalence of BBT use in the sample of 198 cardiovascular patients was $47.5 \%$, which is very similar to the results reported by Eisenberg and colleagues in the general population (42\%) [3]. Comparisons with other investigations of alternative medicine use in cardiovascular patients are difficult to make due to the various definitions of "alternative medicine" [21-25]. Some studies included items such as alternative procedures including acupuncture, while others included "pharmacotherapy" only (herbs, BBT, CAM and nutritional supplements). In addition, certain studies looked at only one cardiovascular disease while others looked at a broad range of patients with multiple diseases. Furthermore, different studies also used different measurements of incidence and prevalence; i.e., some investigators focused on lifetime use, others reviewed the previous 12month history only, yet others limited their findings to BBT use in the 14 days prior to the investigation. Regardless, results indicated that a high percentage of patients with cardiovascular diseases are taking some kind of BBT (almost one out of every two patients). Health care professionals need to be aware of these findings and routinely inquire about BBT use by patients when taking a medication history.

Similar to Ackman's study [21], the most frequently utilized BBT in the present study of cardiovascular patients was vitamin E, (41 [43.6\%]). The popularity of vitamin E among cardiovascular patients is not surprising due to the alleged benefits of this vitamin in heart disease from early literature [12-14], and its relative availability in pharmacies, health food stores and supermarkets. As was the case with vitamin $\mathrm{E}$, the use of vitamin $\mathrm{C}$ in the current investigation, (30 [31.9\%]) was similar to previously reported results, being the second most common product utilized by cardiovascular patients [21].

Similar to other studies $[1,3,6,21]$, the current study confirmed that based on the patients' reports, a high percentage of physicians (40\%) and pharmacists (68\%) were not aware of BBT used by cardiovascular patients. Use of BBT by the patients in this study was not routinely discussed with health care providers during medical history evaluation (33\%). This is an alarming but not an isolated finding. On average, cardiovascular patients consumed 7 (range, 1 - 18) prescribed medications, and 2 (range, 1 12) BBT products. Considering the complex medical treatment received by cardiovascular patients, addition of unmonitored BBT to the patients' regimens may place the users of these therapies at a greater risk for the development of adverse events and interactions with prescribed 
medications. As addressed by this analysis, 42 potential drug-BBT interactions were identified.

\section{Demographics impact on biological based therapy use in cardiovascular patients}

Among the demographic variables collected in this analysis, no parameter other than the level of education had a significant impact on whether patients used BBT. The present investigation revealed that the education level among users (63\% received some college or college and graduate school education) of BBT was higher than that of the nonusers $(32 \%), \mathrm{p}<0.001$. This finding has also been reported in other studies $[3,6]$. Higher level of education has been shown to significantly influence the use of alternative products and services [3]. Education level is sometimes directly related to economic status, thus the patients may have more resources to spend on BBT. Similarly, better-educated consumers may be more likely to be exposed to various less conventional forms of healthcare reading about their illnesses and treatment options. Educated patients also might be less inclined to accept their physicians' knowledge and expertise, and may seek other treatment options.

\section{Perceived safety and efficacy of BBT}

The majority of BBT users (as compared to nonusers) in the current investigation believed that BBT products are safe, effective and cause fewer side effects as compared to prescription medications. These results are consistent with the findings by other investigators $[6,21]$, supporting a logical conclusion that patients who believe that BBT are safe and effective, are more likely to use them.

\section{Study limitations}

Several limitations of the study need to be addressed. Those that are intrinsically related to survey data collection in general include potential bias of responders and nonresponders. Since participation in this study was voluntary, patients who chose to participate in the study may be more motivated and knowledgeable about the subject of BBT as compared to those who refused to participate. Therefore, the results of this study may not be applicable to the entire cardiovascular patient population. Also, a cross-sectional nature of this study precludes drawing any definitive conclusions regarding cause and effect relationships. For example, one cannot definitively conclude that more education will significantly effect one's decision to take BBT because other factors such as exposure to these types of products may have influenced more educated consumers to take these products.

As with other surveys, recall bias cannot be eliminated as data collection relied on patients' self-report, rather than objectively documenting BBT use. Additionally, with surveys there is always a possibility of misunderstanding the questions and responses, miscommunication between the interviewer and the patients, and inaccurate recording of the information. The majority of the survey collected factual information (i.e., demographics and BBT usage history). However, the questions that evaluated patients' perception on the safety and efficacy of conventional medicine and BBT were not validated.

This study was conducted in a large urban inner city hospital; the results may not be extrapolated to other cities or clinical settings. Another limitation may be the exclusion of non-English speaking patients, which may be particularly important since there are certain ethnic groups who are documented to use more BBT than are other ethnic groups (e.g., persons of or from Chinese descent utilize traditional Chinese herbal medications). Finally, terminology varies greatly in the published literature. Some authors use the term CAM in all instances, others differentiate CAM from BBT, etc. As a result, it is very difficult to compare published reports with certainty.

\section{Conclusion}

In recent years, the interest of using BBT in disease management has increased dramatically in the medical and layman communities. The amount of valid scientific research in this area of therapy continues to increase. Yet, there are still many unknowns concerning BBT, especially in the area of adverse effects and drug interactions. The finding of a high prevalence of BBT (47.5\%) use among cardiovascular patients and the lack of communication between patients and their physicians/pharmacists should be addressed by the health care community. Higher education level, as shown in the present study and other previous investigations $[1,3,6,22]$, is associated with an increased use of BBT, but it does not necessarily mean that these patients are aware of the potential detrimental effects of BBT, as demonstrated in the current study. In cardiovascular patients, the perceived effectiveness and safety of BBT, and assumed lack of side effects of these products as opposed to traditional medications, highlights an area for further education. A high incidence of potential drug-BBT interactions was also identified in this study (42 interactions in 94 users). Given that the use of BBT can have a direct effect on patient care, and users of these therapies do not always voluntarily report their use of these products to their providers, health care professionals need to inquire about BBT use routinely. Collecting complete patient histories and educating patients about potential dangers and possibilities of adverse effects and interactions between prescription medications and BBT (or other CAM) will lead to better overall patient care.

\section{Competing interests}

The author(s) declare that they have no competing interests. 


\section{Authors' contributions}

LC participated in literature review, protocol development, collected and analyzed data, and submitted the manuscript for publication. DB collected the data. JWMC participated in study design, data analysis and preparation of manuscript. VR participated in design development and data analysis. HLK proposed the project and reviewed the manuscript. GCC, JM and BM participated in protocol implementation and manuscript review. All authors read and approved the manuscript.

\section{Additional material}

\section{Additional File 1}

Appendix A - Biological based therapy survey, It's a survey tool utilized in the study to collect patient data.

Click here for file

[http://www.biomedcentral.com/content/supplementary/14726882-5-4-S1.doc]

\section{Acknowledgements}

The authors would like to acknowledge LilyAnn Jeu and Urania Rappo for their assistance in data collection

\section{References}

I. Eisenberg DM, Kessler RC, Foster C, Norlock FE, Calkins DR, Delbanco TL: Unconventional medicine in the United States prevalence, costs, and patterns of use. $N$ Engl J Med 1993 , 328:246-252.

2. Complementary and Alternative Medicine Used in the United States [http://nccam.nih.gov/news/graphics.htm]. Accessed 29 June 2004

3. Eisenberg DM, Davis RB, Ettner SL, Appel S, Wilkey S, Rompay MV, Kessler RC: Trends in alternative medicine use in the United States, 1990 - 1997 Results of a follow-up national survey. JAMA 1998, 280: I569-I57.

4. Kesser RC, Davis RB, Foster DF, Van Rompay MI, Walters EE, Wilkey SA, Kaptchuk TJ, Eisenberg DM: Long-term trends in use of complementary and alternative medical therapies in the United States. Ann Intern Med 200I, I35:262-268.

5. Chandola A, Young Y, McAlister J, Axford JS: Use of complementary therapies by patients attending musculoskeletal clinics. I R Soc Med 1999, 92:13-16.

6. Anderson DL, McWhorter LS, Crouch BI, Andersen SJ: Prevalence and patterns of alternative medication use in the university hospital outpatient clinic serving rheumatology and geriatric patients. Pharmacotherapy 2000, 20:958-966

7. Burstein HJ, Gelber S, Guadagnoli E, Weeks JC: Use of alternative medicine by women with early-stage breast cancer. $N$ Engl J Med 1999, 340: I733-1739.

8. Cassileth BR, Luck EJ, Strouse TB, Bodenheimer B]: Contemporary unorthodox treatments in cancer medicine. Ann Intern Med 1984, 101:105-1 12.

9. Fernandez CV, Stutzer CA, MacWilliam L, Fryer C: Alternative and complementary therapy use in pediatric oncology patients in British Columbia: prevalence and reasons for use and nonuse. J Clin Oncol 1998, I 6: I279-1286.

10. Ernst E: Complementary therapies for asthma: what patients use. I Asthma 1998, 35:667-67|.

II. Fairfield KM, Eisenberg DM, Davis RB, Libman H, Phillips RS: Patterns of use, expenditures, and perceived efficacy of complementary and alternative therapies in HIV-infected patients. Arch Intern Med 1998, I 58:2257-2264.

12. Stephens NG, Parsons A, Schofield PM, Kelly F, Cheeseman K, Mitchinson $\mathrm{MJ}$ : Randomized controlled trial of vitamin $E$ in patients with coronary disease: Cambridge Heart Antioxidant Study (CHAOS). Lancet 1996, 347:781-786.

13. Yusuf S, Dagenais G, Pogue J, Bosch J, Sleight P: Vitamin E supplementation and cardiovascular events in high-risk patients. The Heart Outcomes Prevention Evaluation Study Investigators. N Engl J Med 2000, 342:154-160.

14. Rapola JM, Virtamo J, Ripatti S, Huttunen JK, Albanes D, Taylor PR Heinonen OP: Randomized trial of alpha-tocopherol and betacarotene supplements on incidence of major coronary events in men with previous myocardial infraction. Lancet 1997, 349:1715-1720.

15. Duffy SJ, Gokce N, Holbrook M, Huang A, Frei B, Keaney JF Jr, Vita JA: Treatment of hypertension with ascorbic acid. Lancet 1999 , 354:2048-2049.

16. GISSI-Prevenzione Investigators: Dietary supplementation with $\mathrm{n}-3$ polyunsaturated fatty acids and vitamin $E$ after myocardial infarction: results of the GISSI-Prevenzione trial. Gruppo Italiano per lo Studio della Sopravvivenza nell'Infarto miocardico. Lancet I999, 354:447-455.

17. von Schacky C, Angerer P, Kothny W, Theisen K, Mudra H: The effect of dietary omega-3 fatty acids on coronary atherosclerosis. A randomized, double blind, placebo-controlled trial. Ann Intern Med 1999, 130:554-562.

18. Singh RB, Niaz MA, Sharma JP, Kumar R, Rastogi V, Moshiri M: Randomized, double-blind, placebo-controlled trial of fish oil and mustard oil in patients with suspected acute myocardial infarction: the Indian experiment of infarct survival - 4. Cardiovasc Drugs Ther 1997, I I:485-49I.

19. Soja AM, Mortensen SA: Treatment of congestive heart failure with coenzyme $Q \mathbf{~} 10$ illuminated by meta-analyses of clinical trails. Molec Aspects Med 1997, I8: I59-I68.

20. Khatta M, Alexander BS, Krichten CM, Fisher ML, Freudenberger R, Robinson SW, Gottlieb SS: The effect of coenzyme QIO in patients with congestive heart failure. Ann Intern Med 2000, I 32:636-40.

21. Ackman ML, Cambell JB, Buzak KA, Tsuyuki RT, Montague TJ, Teo $\mathrm{KK}$ : Use of nonprescription medications by patients with congestive heart failure. Ann Pharmacother 1999, 33:674-679.

22. Liu EH, Turner LM, Lin SX, Klaus L, Choi LY, Whitworth J, Ting W Oz MC: Use of alternative medicine by patients undergoing cardiac surgery. J Thorac Cardiovasc Surg 2000, I 20:335-4I.

23. Ai AL, Bolling SF: The use of complementary and alternative therapies among middle-aged and older cardiac patients. American Journal of Medical Quality 2002, I 7:21-27.

24. Wood MJ, Stewart RL, Merry H, Johnstone DE, Cox JL: Use of complementary and alternative medical therapies in patients with cardiovascular disease. Am Heart J 2003, I 45:806- I 2

25. Pharand C, Ackman ML, Jackevicius CA, Paradiso-Hardy F, Pearson GJ: Use of OTC and herbal products in patients with cardiovascular disease. Ann Pharmacother 2003, 37:899-904.

26. Reuning RH, Geraets DR, Rocci ML Jr, Vlasses PH: Digoxin. In Applied Pharmacokinetics Principles of Therapeutic Drug Monitoring 3rd edition. Edited by: Evans WE, Schentag J], Jusko WJ, Relling MV. Vancouver, WA: Applied Therapeutics, Inc; 1992:20-29.

27. Porter RS, Sawyer WT: Warfarin. In Applied Pharmacokinetics Principles of Therapeutic Drug Monitoring 3rd edition. Edited by: Evans WE, Schentag JJ, Jusko WJ, Relling MV. Vancouver, WA: Applied Therapeutics, Inc; |992:31-8-31-13.

28. MICROMEDEX $®$ Healthcare Series Integrated Index: Thomson MICROMEDEX. . Vol. 120 expires 6/2004

29. Steiner $M$ : Vitamin $E$, a modifier of platelet function: rationale and use in cardiovascular and cerebrovascular disease. Nutr Rev 1999, 57:306-309.

30. Liede KE, Haukka JK, Saxen LM, Heinonen OP: Increased tendency towards gingival bleeding caused by joint effect of alphatocopherol supplementation and acetylsalicylic acid. Ann Med 1998, 30:542-546.

31. Vitamin E Monograph: Natural Medicines Comprehensive Database. [http://www.naturaldatabase.com]. Accessed April 22, 2001

32. Heck AM, DeWitt BA, Lukes AL: Potential interactions between alternative therapies and warfarin. Am J Health Syst Pharm 2000, 57: $|22|-1227$.

33. Corrigan JJ Jr: The effect of vitamin $E$ on warfarin-induced vitamin K deficiency. Ann N Y Acad Sci 1982, 393:36I-368. 
34. Corrigan JJ Jr, Ulfers LL: Effect of vitamin E on prothrombin levels in warfarin-induced vitamin $\mathbf{K}$ deficiency. Am J Clin Nutr 198I, 34: I70I-I705.

35. Vaes LP, Chyka PA: Interactions of warfarin with garlic, ginger, ginkgo, or ginseng: nature of the evidence. Ann Pharmacother 2000, 34:1478-1482.

36. Miller LG: Herbal medicines: selected clinical considerations focusing on known or potential drug-herb interactions. Arch Intern Med 1998, I58:2200-22I I.

37. Garlic Monograph: Natural Medicines Comprehensive Database. [http://www.naturaldatabase.com]. Accessed April 22, 2001

38. Matthews MK: Association of Gingko biloba and intracranial hemorrhage. Neurology 1998, 50:1934.

39. Sakamoto N, Nishiike T, Iguchi H, Sakamoto K: Effects of eicosapentaenoic acid intake on plasma fibrinolytic and coagulation activity by using physical load in the young. Nutrition 2000, 16: II-I4.

40. Guivernau M, Meza N, Barja P, Roman O: Clinical and experimental study on the long-term effect of dietary gamma-linolenic acid and plasma lipids, platelet aggregation, thromboxane formation and prostacyclin production. Prostaglandins Leurotrienes and Essential Fatty Acids 1994, 5 I:3 I I-3 I6.

4I. Spigset $O$ : Reduced effect of warfarin caused by ubidecarenone. Lancet 1994, 334: 1372-1373.

42. Landbo C, Almdal TP: Interaction between warfarin and coenzyme Q10. (Abstract in English). Ugeskr Laeger 1998, 160:3226-3227.

43. Taylor JR, Wilt VM: Probable antagonism of warfarin by green tea. Ann Pharmacother 1999, 33:426-428.

\section{Pre-publication history}

The pre-publication history for this paper can be accessed here:

http://www.biomedcentral.com/1472-6882/5/4/prepub
Publish with Biomed Central and every scientist can read your work free of charge

"BioMed Central will be the most significant development for disseminating the results of biomedical research in our lifetime. "

Sir Paul Nurse, Cancer Research UK

Your research papers will be:

- available free of charge to the entire biomedical community

- peer reviewed and published immediately upon acceptance

- cited in PubMed and archived on PubMed Central

- yours - you keep the copyright 